\title{
A Taxonomy Of Participation In Online Courses
}

\author{
Regina Bento, University of Baltimore \\ Barry Brownstein, University of Baltimore \\ Edward Kemery, University of Baltimore \\ Susan Rawson Zacur, (E-mail: szacur@ubalt.edu) University of Baltimore
}

\begin{abstract}
One of the main challenges in web-based education is to encourage student participation. Although many instructors would like to increase participation in their online courses, there is no established body of knowledge on the various forms such participation may take. This paper will propose a taxonomy for classifying different types of participation in online courses, discuss pedagogical issues involved in increasing participation, and suggest testable hypotheses for future research.
\end{abstract}

\section{INTRODUCTION}

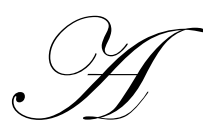

lthough courses have been offered via the Internet for about twenty years, business schools in the United States have significantly increased the number of online course offerings in recent years. This has created interest in pedagogy as it applies to the online environment. There is a growing awareness that faculty teaching online need "to shift their role from knowledge dispenser to facilitator" (Arbaugh, 2005, p. 139) and there is sufficient research to suggest that communication in many online courses should be interactive rather than instructor-centered (Ibid.).

The discussion forum is a key feature in online learning that fosters interaction. Typically, discussion is initiated by a query posted by the professor and pursued by students as they interact with each other to build new understandings asynchronously. Not all online courses will use a discussion forum in the same way. For example, quantitative courses might use this feature as a type of "help desk" where students can post questions about lectures and homework (Brower, 2003). Management courses, which may include organizational behavior, human resource management, strategy, and leadership, tend to use discussion forums to promote interaction, enhance learning, and build community (Ibid.). The faculty leadership role in facilitating the forum is key to student learning.

A challenge for designers and instructors of online management courses is to be able to achieve a level of student participation that supports a learning environment where students play a central role. Pedagogy that is successful in eliciting classroom participation will not necessarily be successful in online courses (Shrivastava, 1999). Bento, Brownstein, Schuster \& Zacur (2005) distinguish between online course designs based on a transmission model of course design where the instructor plays the central role as the "sage on the stage" and the transformation model of course design where professor and student co-create the learning environment. In the latter model the professor's role becomes that of a "guide on the side."

Collison, Elbaum, Haavind, and Tinker (2000) provide the advantages of the transformation or the "guide on the side" model:

"As participants react to content, share challenges, teach each other, and learn tangibly by putting into words (discussion postings) their own understandings and clarifications of assumptions, they experiment with and eventually take ownership of new skills and ideas. All along, the "guide on the side" serves to focus and deepen the dialogue without getting in the way of participants' development of their own expertise." 
McMaster (1997) cautions against the top down approach to learning as he observes, "we tend to apply the engineering approach to information and learning. We think that by giving information to people, whether in a classroom or manual, we have given them knowledge." Once however that you understand that the true nature of knowledge is "always and only implicit and self-generated" (Ibid.) then you understand that knowledge is not easily transferred by the "sage on the stage." To turn information into knowledge a student has to make personal meaning of the information. McMaster (Ibid., p. 95) observes that "intelligence comes into being and creates meaning from dialogue, conversations, and community."

An online management class is inherently student-centric rather than professor-centric. Without the visible presence inherent in real-time interaction in a classroom, some students may decrease the frequency and quality of their participation. Online instructors often react to this by increasing the percentage of the grade that is tied to participation in the discussion boards. This reward and punishment strategy may not work if students are unclear about how to be "good" or "bad" online participants. For example, not all "bystanders" are goofing off, and not all discussion participants are learning.

Reward and punishment should not be the first thing we turn to when trying to increase participation. Educator Alfie Kohn (1999) strongly opposes punishment and reward systems in education observing that both "proceed from basically the same psychological model, one that conceives of motivation as nothing more than the manipulation of behavior." Although his research is not directly with students, Deci (1996) has observed two problems with controlling behavior as a solution to increasing participation. First, according to Deci, the approach is counter-productive: "If people are ongoingly treated as if they were either passive mechanisms or barbarians needing to be controlled, they will begin to act more and more that way." Second, Deci's research shows that "any occurrence that undermines people's feelings of autonomy - that leaves them feeling controlled decreases their intrinsic motivation." (Ibid)

\section{A TAXONOMY OF PARTICIPATION}

In online courses requiring discussion, two different interactions must occur. First, the student must read, reflect on, and interact with course materials in order to form the ideas necessary for posting thoughts. Moore (1998) calls this "learner-content interaction" and deems it essential for changes to occur in the learner's understanding and perspective. Berge (1998) calls this "interaction with content" and supports Moore's emphasis on this key component of learning. The second interaction takes place between learners, whether it be other students or between faculty and student as co-learners. Moore (1998) call this "learner-learner interaction" and "learner-instructor interaction" while Berge (1998) more broadly defines it as "interpersonal interaction" stating that "interpersonal interaction offers the opportunity for the student to gain the motivational support of fellow students and instructors, develop critical judgment, and participation in problem solving." (Ibid. p.28) In order to provide a deeper understanding of online participation, its causes and consequences, this paper presents a taxonomy of the types of behavior typical of students in online courses that require discussion of issues and cases. The taxonomy proposed here is based on Moore's (1989, 1996) and Berge's (1998) discussions of types of interaction in distance education.

As represented in Figure I, the taxonomy plots different types of participation into four quadrants, determined by a horizontal axis that corresponds to Berge's "Interaction with Content" and a vertical axis that corresponds to Berge's "Interpersonal Interaction."

Students in Quadrant IV ("Active Learners") represent what online instructors truly mean by "good participation." They are high on both Content Interaction and Interpersonal Interaction. Their contributions to online discussions are both substantive and frequent. They contribute to ongoing thought and to building and sustaining relationships in the learning community.

The literature on behaviors conducive to the effectiveness of face-to-face teams can be applied to our understanding of Quadrant IV interactions. Whetten and Cameron (1998, pp. 433 and 434) provide an excellent description of the behaviors necessary for task-facilitating (direction giving, information seeking, information giving, elaborating, coordinating, monitoring, process analyzing, reality testing, enforcing, summarizing) and for relationship 
building (supporting, harmonizing, tension relieving, confronting, energizing, developing, facilitating, processing). Some "Active Learners" may specialize in some of these roles, or may take them on as necessary. The critical point is "to ensure that these roles are fulfilled, so that the team can function effectively." (McShane \& Von Glinow, 2000, p. 284). If online students in a class can be considered to be part of a large team of learners, they can become acquainted with these behaviors in the course introduction and invited to choose those roles that they wish to play in online discussions.

Figure I - Taxonomy of Participation in Online Courses

\begin{tabular}{|c|c|c|}
\hline & QUADRANT III & QUADRANT IV \\
\hline & "Social Participants" & "Active Learners" \\
\hline & & \\
\hline & & \\
\hline & QUADRANT I & QUADRANT II \\
\hline & "Missing in Action" & "Witness Learners" \\
\hline & & \\
\hline
\end{tabular}

Quadrants III and IV both share the characteristic of high Interpersonal Interaction. These are highly visible students, who often participate in the online discussions. But an analysis of the kind of contributions they bring to the discussion reveals that they differ fundamentally in terms of their Content Interaction.

Students in Quadrant III (High Interpersonal Interaction, Low Content Interaction) provide numerous postings. The motivation behind these students may differ. Some post often because they believe that the frequency of contribution will result in a high grade. Others may thrive on the social aspect of the online discussions. These "Social Participants" are great on-line conversationalists. Despite motivational difference, the problem with students in this quadrant is that they produce much "on-line clutter", at the expense of reflection and thoughtful consideration of course content.

It is important to differentiate high and low content interaction in the case of students with high interpersonal interaction so that instructors can help the "social participants" to correct the limitations in their style of participation. If the online instructor doesn't carefully analyze "participation," and just goes by surrogate measures such as number of entries, or average number of words per entry, the lack of learning on the part of "social participants" may go undetected, and may even end up being over-rewarded with high grades. If undetected, the Quadrant III student loses because of inadequate learning. If detected, but not sufficiently oriented to what is expected (in terms of both high interpersonal interaction and high content interaction), this student may feel the victim of a gross inequity: "I participated so much, how come you gave me a bad grade?"

The two bottom quadrants (I, II) share the characteristic of low interpersonal interaction. These are "invisible" students, the "bystanders" who do not actively participate in the online discussions. Instructors often perceive them as a single category of "non-participants," from which it is inferred that they are not learning, and which often leads to lower grades. Although many instructors might infer that these students are not learning, Figure I reveals that there are two very different dynamics going on behind the same mantle of "invisibility." 
The bystanders in Quadrant I represent the kind of non-participation that might be called "missing in action." Frequently, it leads to all sorts of negative attributions towards those students who are "missing" and it is inferred that they neither care about the course content nor their peers' learning. Students in this quadrant often do not learn much, achieve a disastrous grade, or end up quitting the course.

"Missing in action" students frequently present the greatest challenge in increasing participation. Some who fall into this category are unready for on-line learning. Reasons for this include signing up for a web course under the mistaken belief that it will take less time to complete the course work than the corresponding face-to-face course, being new to a web course and simply bewildered by a "classroom" that is not professor-centric, or not having the technological capability to participate fully, resulting in frustration and low participation. Because reasons for these "missing in action" students differ, it is critical that the instructor communicate with them early in the semester in order to understand their needs.

In these cases the answers are the same. First, a very clear syllabus and course site that spells out in detail the rules of participation in the course is necessary. Second, very timely and direct feedback to the student when they are not following the rules is critical. The feedback should be firm but kind. "Firm but kind" means that the feedback should be perceived by the student as informational rather than judgmental and that there is room in the instructor's mind for the student to evolve. Nevertheless, since some students in web courses are taking the course under the mistaken impression that less time is needed to fulfill their academic obligations, there may be more course withdrawals than in a corresponding face-to-face course.

Although the bystanders in Quadrant II may seem equally "invisible," their dynamic is entirely different. These are the "witness learners (Fritsch, 1997)," who are actively engaged with the course materials, log in frequently and do all the readings, but do not actively contribute to the online discourse (low Interpersonal Interaction). For the witness learner, learning is still taking place, albeit in a more passive and less visible way (Ibid.).

Like the missing in action student, motivations for witness learners are equally diverse. Students for whom English is a second language may not feel comfortable expressing themselves in a written forum - they are learning, just not contributing. Students with low self-esteem or negative affectivity may feel hesitant to contribute for fear of rejection. Students who have not had their contributions acknowledged or have had them rejected in the forum environment may have chosen to decrease their participation. No matter what the reason, these students are depriving the class of their valuable insights.

A study of "invisible" students in an online graduate course (Beaudoin, 2002) highlights the importance of not lumping together "witness learners" with the "missing in action" bystanders. Beaudoin found out that "witness learners" are indeed learning, and can perform even better in graded assignments than students with average visibility, although not as well as those with high visibility. Beaudoin compares their learning strategies to an iceberg: there's much more than meets the eye. But Beaudoin offers an important caution about witness learners: while it is important to understand the causes behind low visibility participation at certain points along the way of an online course and to determine if learning-related activities are still taking place "behind the scenes," this should not be interpreted as a blanket endorsement of all forms of low visibility.

\section{PROVIDING EFFECTIVE ONLINE LEADERSHIP}

A goal of professors in an online learning class is to maximize the number of students in Quadrant IV. That is, a professor must provide the leadership to move students in Quadrants I, II, \& III to Quadrant IV. In order to understand how these shifts might be accomplished, it will be helpful to think of the professor as a leader who must respond differently to each student, depending on their taxonomic location. Situational leadership (Hersey and Blanchard, 1969) provides us with insights regarding how to focus our efforts.

Situational leadership theory (SLT; Hersey \& Blanchard, 1982, 1969) suggests that leadership efforts must match characteristics of the subordinate. To capture relevant subordinate characteristics, Hersey and Blanchard (1982) created a term referred to as maturity. Maturity contains two concepts - willingness and ability. Willingness 
has to do with motivation; ranging from those who are unmotivated (unwilling) to those who are highly motivated (willing). Ability refers to capacity for performing a task, and ranges from unable to able.

According to SLT, a leader must first identify a subordinate's characteristics and then adapt his/her leadership style accordingly. For example, those who are unable/unwilling will benefit from a different leadership style than those who are able/willing. In the former instance, a combination of task structure and motivation is needed, while in the latter instance, a more collegial approach is suggested.

In placing SLT in an online context, Kemery (2000) used the concept of student readiness for online learning (SROL). As shown in Figure 2, SROL consists of two elements: technology skills and online learning skills. Consistent with SLT, an instructor's approach for maximizing student learning online, will depend on SROL. For example, those students who fall into Quadrant A in Figure 2 (those who are deficient in both technology skills and cooperative online learning skills) must acquire both skill sets in order to fully benefit from an online course. In contrast, those in Quadrant D are fully prepared and thus set to maximize their learning in an online course.

Figure 2. Student Readiness for On-Line Collaborative Learning

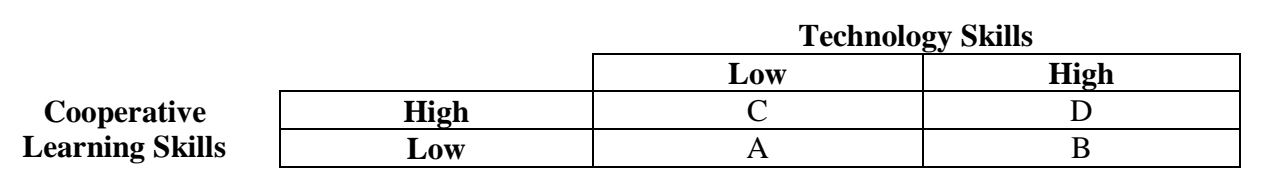

Within the context of our taxonomy, the primary challenge is to move students in Quadrants I, II, and III to Quadrant IV. In light of SLT and SROL, the strategy selected by the instructor must match the characteristics and needs of the student. Witness learners are perhaps the easiest to move to the "active learner" quadrant. They are serious students who already have a high involvement with the material. If the course syllabus sets out the rules of participation clearly and if the instructor has helped to establish an atmosphere of safety (as described below) witness learners should gradually increase their participation and by course end, there should be only a few of these students. Gentle encouragement and feedback will help move those students into the highest category.

How is an atmosphere of safety established? Regardless of the course content it is very useful to instruct students on the difference between dialogue and debate very early in the semester. Michael McMaster (1996) defines a dialogue as "conversation in which the intention is to generate something in the conversation itself that did not exist in any one of the participants before the conversation began." Students should be taught that in a healthy dialogue we learn to listen or read without judgment in order to understand what is being conveyed. Listening without judgment does not mean shutting down your critical facilities or agreeing with what you are reading but it does mean giving the space to the author to be heard first. (Ellinor \&Gerard,1998) Without the fear of being judged, an atmosphere of safety is created that allows for the maximum number of students to move to the quadrant of "active learners". Students report that the skill of dialogue is something that is frequently valuable in other courses as well as in their personal and professional relationships.

Fostering student online participation begins with the instructor (Bento, Brownstein, Schuster \& Zacur, 2005). Most importantly, the instructor must approach the online course in a wholehearted fashion. Online courses take considerably more work for the faculty member than the same course taught face-to-face. The instructor must approach the online course assignment with the attitude of a co-learner and with enthusiasm for the course material. For students to be fully engaged as "active learners," their instructors must demonstrate engagement. Full engagement begins with the choice of course material. Professors, through words and actions, communicate passion or lack of passion for the course material and for learning. The course material should be fresh and alive in the instructor and when it is both teaching and communications will be exciting. If course reading material is mostly second hand sources that remove excitement from the learning material, it is hard for anyone to engage in the course material and be an "active learner". The Arbinger Institute (2001) observes succinctly: "After all, nothing is so drab and dreary as having to find a way to learn in the presence of someone who has given up learning." Similarly, educator Parker 
Palmer (1999) quotes a student speaking about classroom professors (but his observations are applicable to any learning environment): "One student I heard said she could not describe her good teachers because they differed so greatly, one from another. But she could describe her bad teachers because they were all the same: 'Their words float somewhere in front of their faces, like the balloon speech in cartoons."' Good online teachers are educational facilitators. In addition to choosing lively, original sources for readings, as mentioned previously, online instructors develop questions and activities for learners that encourage students to relate their own experiences to the text materials (Berge, 1995). They attend to student postings not only for the purpose of individual evaluation and feedback, but also for the purpose of linking student contributions into unifying themes for further comment. Teachers thus help to articulate the insights that are emerging so that students can experience the development of new knowledge that they and their co-learners are producing." (Ibid.)

When difficulties arise, professors' reactions will determine whether the negative effect will be lasting. Professors must first show respect for the student as a human being and then next as a learner who can evolve. This allows respect (but not necessarily a good grade) for those students who ultimately choose not to evolve and increase their participation. By demonstrating respect for each student, a sense of safety is created in which participation can flourish. Given respect and firm but kind guidance, most students will evolve toward "active learners".

Within the context of our taxonomy, how do "social participants" and others in Quadrant III become "active learners" (Quadrant IV)? One strategy is to create clear expectations and provide on-going feedback. Dee Hock, the founding CEO of Visa has observed that the most effective way to operate an organization is to understand that: "Simple, clear purpose and principles give rise to complex, intelligent behavior. Complex rules and regulations give rise to simple, stupid behavior." (Hock, 1999) Hock's maxim has great applicability for the effective design of an online web environment. There must be clear rules set out in the course syllabus that explain to students the required weekly rhythm of the online forum (the forum is the area of an online course where the weekly dialogue takes place) and what constitutes an effective post to the forum. A few sample postings can illustrate what is expected in content. These rules, although very specific, can be simple in that they allow the student to engage the reading material in ways that make the most sense to them given their background and experience. Rules that are complex, that require the student to meet the material in a way that is not meaningful to them, will quickly inhibit participation. For example, requiring all students in an online course in international economics to research the same country as opposed to a country of their own interest, will quickly diminish motivation and participation.

Another strategy for moving "social participants" and others in Quadrant III into the category of "active learners," is to elucidate a clear rule against "shop talk." A post is "shop talk" if a student could have written it without having taken this course or without having read any of the readings. "Shop talk" generates a lot of forum posts with little net content for professors and students to read. Although a certain amount of "shop talk" is unavoidable and fun, it is important to keep it to a minimum. "Shop talk" is reduced by giving Quadrant III students clear and direct feedback that they need to make greater use of the course material in their forum posts. When they do this, evidence of their learning is improved and the learning atmosphere of the class is enhanced as the quality of the forum interaction increases.

Those students who have reached Quadrant IV - those with high content and high interaction are best poised to thrive in an online course. And, while it is important for an instructor to focus on the other students, it is also important to reinforce those in Quadrant IV. These students should be challenged to work towards even higher conceptual understanding.

\section{CONCLUDING THOUGHTS}

The taxonomy proposed here has direct implications for practice and research in online education. It is crucially important, for pedagogical and fairness reasons, that online instructors take active measures to differentiate "witness students" from those "missing in action." By contacting early and often the low visibility students, an instructor can help a student move from Quadrant I ("missing in action") to Quadrant II ("witness learner), and from there to the most desirable Quadrant IV ("Active learner"). 
The awareness that high interpersonal interaction does not equate with "good participation" unless it is accompanied by high content interaction should also help online instructors to differentiate between "Social Participants" and "Active learners." Such differentiation is essential for instructors to identify "Social Participants," to avoid over-rewarding into a false sense of complacency, and to help them improve their content interaction. Moving from Quadrant III to Quadrant IV allows the "Social Participants" to more fully benefit from, and contribute to the online community they enjoy so much.

There is growing evidence that increased participation (in quality and quantity) can increase learning and that instructors can control a series of elements in course design and delivery that may result in increased participation (Harasim et al, 1995; Kemery, 2000). If instructors are able to move more students into Quadrant IV, and keep those who are there from sliding back into other Quadrants, the practical benefits for individual and collective learning can be significant.

\section{IMPLICATIONS FOR FURTHER RESEARCH}

Our measures of performance in online courses need to be refined, and extended beyond the course boundaries to assess the degree to which students are able to apply what they learn in class to their own work environments. We also need to deepen our understanding of how the participation of individual learners can impact the learning process for themselves and for the other learners as well.

The implications for future research are numerous. For example, the taxonomy opens multiple areas of investigation in terms of the antecedents of the various types of participation. How do variables such as course design, technology, characteristics and behaviors of both instructors and students (gender, age, personality, cognitive style, cultural and professional backgrounds, etc) affect the relative frequency of students in quadrants I, II, III and IV? What factors affect the intensity, direction and speed of movement between different combinations of quadrants?

Another intriguing set of questions involves the consequences of the various types of participation. What are the effects of permanence in a certain quadrant, or movement between quadrants, on dependent variables such as: learning, grades, satisfaction with course, teacher evaluations, self-efficacy, self-esteem, type of participation in future courses (with the same peers and instructor, or with different ones), graduation rates, loyalty towards the institution?

The answers to those questions can directly affect the level of learning that students achieve in online courses, and may even spillover into their ability to improve participation in other types of distance education and traditional face-to-face classes. Learning how to improve course participation may in turn influence, in the longer run, their ability to effectively participate in virtual and face-to-face teams in the workplace.

\section{REFERENCES}

1. Arbaugh, J.B. (2005). Is There an Optimal Design for On-Line MBA Courses? Academy of Management Learning \& Education 4(2) pp.135 - 149.

2. The Arbinger Institute (2001). The Choice in Teaching and Education. Salt Lake City, Utah: The Arbinger Institute. p.48.

3. Beaudoin, M. F. (2002). Learning or Lurking? Tracking the 'Invisible' Online Student. Draft shared by author in advance of publication.

4. Bento, R; Brownstein, B.; Schuster, C. \& Zacur, S. (2005). Fostering Online Student Participation. Journal of College Teaching and Learning, 2 (7):31-37.

5. Berge, Z. L. (1998). Conceptual Frameworks in Distance Training and Education. In Deborah Schreiber and Zane L. Berge, Eds. Distance Training: How innovative organizations are using technology to maximize learning and meet business objectives. San Francisco: Jossey-Bass. pp.19- 36.

6. Berge, Z.L. (1995) Facilitating Computer Conferencing: Recommendations From the Field. Educational Technology. 35(1): pp. 22-30.

7. Brower (2003). On Emulating Classroom Discussion in a Distance Delivered OBHR Course: Creating an Online Learning Community. Academy of Management Learning and Education, 2 (1): pp. 22-36. 
8. Collison, G.; Elbaum, B.; Haavind, S.; Tinker, R. (2000). Facilitating Online Learning. Madison, WI: Atwood Publishing, p.8.

9. Deci, E. (1996). Why We Do What We Do. New York, New York Penguin, p. 21.

10. Ellinor, L. and Gerard, G. (1998). Dialogue: Rediscover the Transforming Power of Conversation. New York, New York: John Wiley.

11. Fritsch, H. (1997). Host contacted, waiting for reply. (Evaluation report of virtual seminar held January March, 1997).

12. Harasim, L., Hiltz, S.R., Teles, L. \& Turoff, M. (1995). Learning Networks: A field guide to teaching and learning online. Cambridge, MA.: MIT Press.

13. Hersey, P. \& Blanchard, K.H. (1969) Life Cycle Theory of Leadership. Training and Development Journal, 23(1969: pp. 26-30).

14. Hersey, P. \& Blanchard, K. H. (1982) Management of Organizational Behavior: Utilizing Human Resources. Englewood Cliffs, N.J.: Prentice-Hall,

15. Hock, D. (1999). Birth of the Chaodic Age. San Francisco, CA. Berrett-Koehler, p. 120.

16. Kemery, E. (2000). Developing Online Collaboration. In Anil Aggarwal, Ed. Web-Based Learning and Teaching Technologies: Opportunities and challenges. Hershey, PA: Idea Group Publishing. pp. 227-245.

17. Kohn, A. (1999). Punished by Rewards. Boston, MA.: Houghton-Mifflin Co., p. 121.

18. McMaster, M. (1996). The Intelligence Advantage. Newton, MA.:Butterworth-Heinemann, p.215.

19. McMaster, M. (1997). The Praxis Equation. Isle of Man: Knowledge Based Development Corporation, pp. 95-96.

20. McShane, S. L., \& Von Glinow.M.A. (2000). Organizational Behavior: Emerging realities for the workplace revolution. Irwin-McGraw-Hill.

21. Moore, M. G. (1989). Three Types of Interaction. The American Journal of Distance Education, 3 (2): 1-6.

22. Moore, M. G. \& Kearsley, G. (1996). Distance Education: A systems view. Belmont, CA: Wadsworth.

23. Palmer, P. (1998). The Courage to Teach. San Francisco, CA: Jossey Bass, p. 11.

24. Shrivastava, P. (1999). Management Classes as Online Learning Communities. Journal of Management Education, 23 (6): 691-703.

25. Whetten, David A. \& Cameron, Kim S. (1998). Developing Managerial Skills. $4^{\text {th }}$ ed. Reading, MA: Addison-Wesley. 